\title{
A coherent picture of the hydrogen oxidation and evolution reactions in aqueous solutions
}

Ershuai $\mathrm{Liu}^{1}$, Li Jiao², Jingkun $\mathrm{Li}^{1,3}$, Thomas Stracensky ${ }^{1}$, Lynne Larochelle Richard ${ }^{1}$, Qiang

Sun $^{1}$, Sanjeev Mukerjee ${ }^{1}$, and Qingying Jia*,1

${ }^{1}$ Department of Chemistry and Chemical Biology, Northeastern University, Boston, Massachusetts, 02115, United States

${ }^{2}$ Department of Chemical Engineering, Northeastern University, Boston, Massachusetts, 02115, United States

${ }^{3}$ Institut Charles Gerhardt Montpellier, UMR 5253, CNRS, Université Montpellier, ENSCM, Place Eugène Bataillon, 34095 Montpellier cedex 5, France

${ }^{1}$ is the previous address of J.L.; ${ }^{3}$ is the present address.

*Correspondence authors. q.jia@northeastern.edu (Q. J.) 
Abstract. Recent studies show the limitations of catalytic activity descriptor-based approaches to rationalize the kinetics of the hydrogen oxidation and evolution reactions (HOR/HER). Herein, we deposited several transition metals (TMs) onto Pt surfaces to disturb and probe the interface in alkaline solutions. The redox transition of these TMs in association with adsorption and desorption of reaction intermediates during the HOR/HER was monitored via in situ X-ray absorption spectroscopy. We propose that the TM facilitates the HOR by anchoring $\mathrm{H}_{2} \mathrm{O}$ with the H-up configuration ( $\left.\uparrow \mathrm{H}_{2} \mathrm{O}_{\mathrm{ad}}\right)$ that removes $\mathrm{H}_{\mathrm{ad}}$ on Pt via the bifunctional mechanism, based on the first in situ experimental evidence for the presence of $\uparrow \mathrm{H}_{2} \mathrm{O}_{\text {ad }}$ on surface Ru. Meanwhile, the TM promotes the HER of Pt by anchoring $\mathrm{OH}_{a d}$ to trigger the hard-soft acid-base (HSAB) mechanism for $\mathrm{OH}_{\mathrm{ad}}$ removal. The revised 2B theory depicts a coherent picture of the HOR/HER kinetics in aqueous solutions.

Hydrogen oxidation and evolution reactions (HOR/HER) describe the electrochemical transformations between $\mathrm{H}_{2}$ and water. They underlie the future hydrogen economy that relies on efficient consumption of $\mathrm{H}_{2}$ such as in fuel cells and feasible production of $\mathrm{H}_{2}$ from water such as in electrolyzers. In addition to their practical importance, the HOR/HER are the most fundamental electrochemical reactions. Studies of the HOR/HER kinetics in acidic solutions led to the establishment of underlying principles in electrochemistry such as the Butler-Volmer equation ${ }^{1}$ and Sabatier's principle. ${ }^{2}$ The HOR/HER activities of a broad range of elements in acidic solutions exhibit a volcano trend as a function of the metal-H binding energy $\left(\mathrm{E}_{\mathrm{M}-\mathrm{H}}\right)$, with Pt sitting near the top as per the Sabatier's principle. ${ }^{3}$ However, this coherent picture of the HOR/HER kinetics in acidic solutions is not fully applicable when extending to alkaline solutions. The HOR/HER rates of several elements including Rh, Pd, Ir, Pt, and Au are all slower 
in alkaline solution than in acid, no matter whether the $\mathrm{E}_{\mathrm{M}-\mathrm{H}}$ is too strong or weak, or nearly optimistic. ${ }^{4}$ The breakdown of the Sabatier's principle in the HOR/HER kinetics across a wide $\mathrm{pH}$ range implicates that the volcano activity trend dictated by the $\mathrm{E}_{\mathrm{M}-\mathrm{H}}$ depicts only a limited scene of the HOR/HER, and a more general picture is to be discovered.

The HOR/HER rates of Pt not only slow down when switching from acidic to alkaline solutions, but also become sensitive to surface structures. For example, the alkaline HOR/HER kinetics of the $\mathrm{Pt}(110)$ facet is faster than that of $\mathrm{Pt}(111) .{ }^{5}$ In addition, it was lately found that the HOR/HER rates of Pt surfaces other than $\mathrm{Pt}(111)$ (non-Pt(111)) are sensitive to alkali cations $\left(\mathrm{AM}^{+}\right)$in alkaline solutions. The HOR/HER rates of non-Pt(111) surfaces decrease in the sequence of $\mathrm{LiOH}>\mathrm{NaOH}>\mathrm{KOH} .{ }^{6,7}$ Meanwhile, the HER improves whereas the HOR rate remains largely unchanged with increasing $\mathrm{AM}^{+}$concentration. ${ }^{6,8-10}$ These $\mathrm{AM}^{+}$-induced effects are, however, absent for the Pt(111) surface. ${ }^{10,11}$ Moreover, the HOR/HER rates of Pt in alkaline solutions can be changed by decorating the Pt surface with a second transition metal (TM), and the change varies drastically depending on the identity of the TM. Surface Ru greatly improves the HOR/HER of Pt in alkaline solutions. ${ }^{11-13}$ Surface Ni improves the HER markedly, ${ }^{6,7,13,14}$ but HOR marginally, ${ }^{6,7}$ whereas surface Co promotes the HER but lowers the HOR rate of Pt(111). ${ }^{7}$ The high sensitivities of the HOR/HER rates of Pt in alkaline solutions to $\mathrm{pH}$, surface structure, $\mathrm{AM}^{+}$identity and concentration, and TM identity have not been unified into a coherent picture by one theory.

Table 1 Summary of current theories for the HOR/HER.

\begin{tabular}{cccccc}
\hline \multicolumn{5}{c}{ HER } & \multicolumn{3}{c}{ HOR } \\
\hline & $\operatorname{Pt}(111)$ & Non-Pt(111) & $\operatorname{Pt}(111)$ & Non-Pt(111) & Proposed theory \\
\hline $\mathrm{pH}$ & $\sqrt{ }$ & $\sqrt{ }$ & $\sqrt{ }$ & $\sqrt{ }$ & $\mathrm{pzfc}^{14}, \mathrm{HBE}^{15}$ \\
$\mathrm{AM}^{+}$Identity & - & $\sqrt{ }$ & - & $\sqrt{ }$ & $\mathrm{HBE}^{10}, \mathrm{BB}^{6}$ \\
$\mathrm{AM}^{+}$Conc. & - & $\sqrt{ }$ & - & - & Bifunctional $^{8}, 2 \mathrm{~B}^{6}$ \\
$\mathrm{TM}$ & $\sqrt{ }$ & $\sqrt{ }$ & $\sqrt{ }$ & $\sqrt{ }$ & All $^{6,12-14,16}$ \\
\hline
\end{tabular}

- means ineffective, $\sqrt{ }$ means effective. 
Several theories have been proposed to account for these HOR/HER activity sensitivities (Table 1). Each of them works in some circumstances but fails in others. Koper et al. ${ }^{14,17}$ proposed that the $\mathrm{pH}$-dependent HOR/HER activity of Pt is caused by the pH-dependent potential of zero free charge (pzfc) that dictates the flexibility of water molecules in the innerHelmholtz Plane (IHP) (pzfc theory). Whereas Yan et al. ${ }^{15,18,19}$ ascribed it to the pH-dependent $\mathrm{E}_{\mathrm{Pt}-\mathrm{H}}$ (HBE theory). Markovic et al..$^{13,20,21}$ ascribed the slower HOR/HER kinetics of Pt in alkaline than in acidic solutions to the need to dissociate $\mathrm{H}_{2} \mathrm{O}$ to provide $\mathrm{H}_{\mathrm{ad}}$. According to these arguments, the pH-induced change of the pzfc, HBE, or $\mathrm{H}_{\mathrm{ad}}$ source affect both the HOR/HER as reversible reactions. These theories are thus theoretically plausible for the circumstances wherein the HOR/HER rates move together such as changing the surface structure, $\mathrm{AM}^{+}$identity, or adding surface Ru, but implausible for the cases that only the HER improves such as increasing $\mathrm{AM}^{+}$concentration ${ }^{6}$ or inducing surface $\mathrm{Co}^{7}$ (Table 1 ). We recently explained the $\mathrm{AM}^{+}$-induced selective HER improvement as the hydrated $\mathrm{AM}^{+}$facilitate releasing the intermediate $\mathrm{OH}_{\text {ad }}$ into the bulk via the hard-soft acid-base (HSAB) theory: $\mathrm{OH}_{\mathrm{ad}}-\left[\mathrm{AM}\left(\mathrm{H}_{2} \mathrm{O}\right)_{\mathrm{x}}\right]^{+}+\mathrm{e}^{-} \rightarrow \mathrm{OH}^{-}-$ [AM( $\left.\left(\mathrm{H}_{2} \mathrm{O}\right)_{\mathrm{x}}\right]^{+}$, and the surface $\mathrm{Ni}$ or Ru helps the HER in this regard by anchoring $\mathrm{OH}_{\mathrm{ad}}$ to trigger the HSAB. ${ }^{6}$ Accordingly, the surface $\mathrm{Ni}$ or $\mathrm{Ru}^{12}$ induced-HOR improvement was ascribed to the bifunctional mechanism proposed by Markovic et al. ${ }^{13}$ wherein the hosted $\mathrm{OH}_{\mathrm{ad}}$ removes $\mathrm{H}_{\mathrm{ad}}$. This so-called 2B theory however fails to account for a recent finding by Tang's group ${ }^{7}$ that the surface Co improves the HER but not the HOR of Pt in alkaline solutions, given that the Co can anchor $\mathrm{OH}_{\mathrm{ad}}$ like $\mathrm{Ni}$ and thus shall improve the HOR. Moreover, the participation of $\mathrm{OH}_{\mathrm{ad}}$ in the HOR/HER of Pt was ruled out by kinetics analysis. ${ }^{22}$ Apparently, a universal theory that can account for all these circumstances is missing. 
Herein, by depositing several TMs onto Pt surface to probe its HOR/HER interface in alkaline solutions with the help of X-ray absorption spectroscopy (XAS), we gave the first in situ experimental evidence for the specific adsorption of $\mathrm{H}_{2} \mathrm{O}$ with the $\mathrm{H}$-up configuration (denoted as $\uparrow \mathrm{H}_{2} \mathrm{O}_{\text {ad }}$ ) during the HOR. We accordingly propose that the HOR kinetics of non-Pt(111) surfaces in alkaline solutions is governed by the revised bifunctional mechanism wherein it is the $\uparrow \mathrm{H}_{2} \mathrm{O}_{\text {ad }}$ rather than $\mathrm{OH}_{\text {ad }}$ that oxidatively remove the $\mathrm{H}_{\text {add }}$. The revised 2B theory, which combines the revised bifunctional mechanism and the HSAB mechanism, appears to be compatible with all circumstances aforementioned, and gives a coherent picture of the HOR/HER kinetics in aqueous solutions.

The TM was electrochemically deposited onto a Pt polycrystalline electrode by immersing the electrode into the TM solution, following our previous protocol that allows for modulating the TM coverage on Pt surfaces by tuning the concentration of the solution. ${ }^{6,12}$ The HOR/HER polarization curves of the bare and deposited electrode were obtained in a rotating disk electrode in a $\mathrm{H}_{2}$-saturated $0.1 \mathrm{M} \mathrm{KOH}$ electrolyte. The TM-induced changes of the HOR/HER rates of Pt vary dramatically with the identity of TM, and accordingly are categorized into three quadrants in the Cartesian coordinate system, together with the representative polarization curves (Figure 1). Ru and Ni improve both the HOR/HER rates of Pt, in consistent with the literature. ${ }^{11-14,20} \mathrm{Mn}, \mathrm{Fe}$, and Co improve the HER but decrease the HOR rate of Pt, in agreement with Tang et al's recent results. ${ }^{7}$ In the case of $20 \mu \mathrm{M} \mathrm{Co}\left(\mathrm{ClO}_{4}\right)_{2}$ when the Co-induced blocking effect is insignificant as evidenced by the negligible change of the HOR limiting current density and the cyclic voltammetry (CV) (Figure S1), the significant HER rate improvement verifies that surface Co improves the HER kinetics of Pt, whereas the trivial decrease of the HOR rate suggests that Co has insignificant effects on the HOR kinetics other 
than blocking the surface. Both the HOR/HER rates decrease for a higher Co coverage by increasing the concentration of $\mathrm{Co}\left(\mathrm{ClO}_{4}\right)_{2}$ to $100 \mu \mathrm{M}$ because of the blocking effect (Figure 1, quadrant IV). Similarly, the HOR/HER rates of Pt slights decrease with $20 \mu \mathrm{M} \mathrm{Cu}^{2+}$, and keep decreasing with increasing $\mathrm{Cu}^{2+}$ concentration (Figure 1, quadrant III), which indicates that surface $\mathrm{Cu}^{2+}$ also has negligible effects on the HOR/HER kinetics of Pt, and the decrease of the HOR/HER rates comes mainly from the blocking effect. Finally, selective improvement of the HOR without improving the HER is not seen here, or anywhere else.

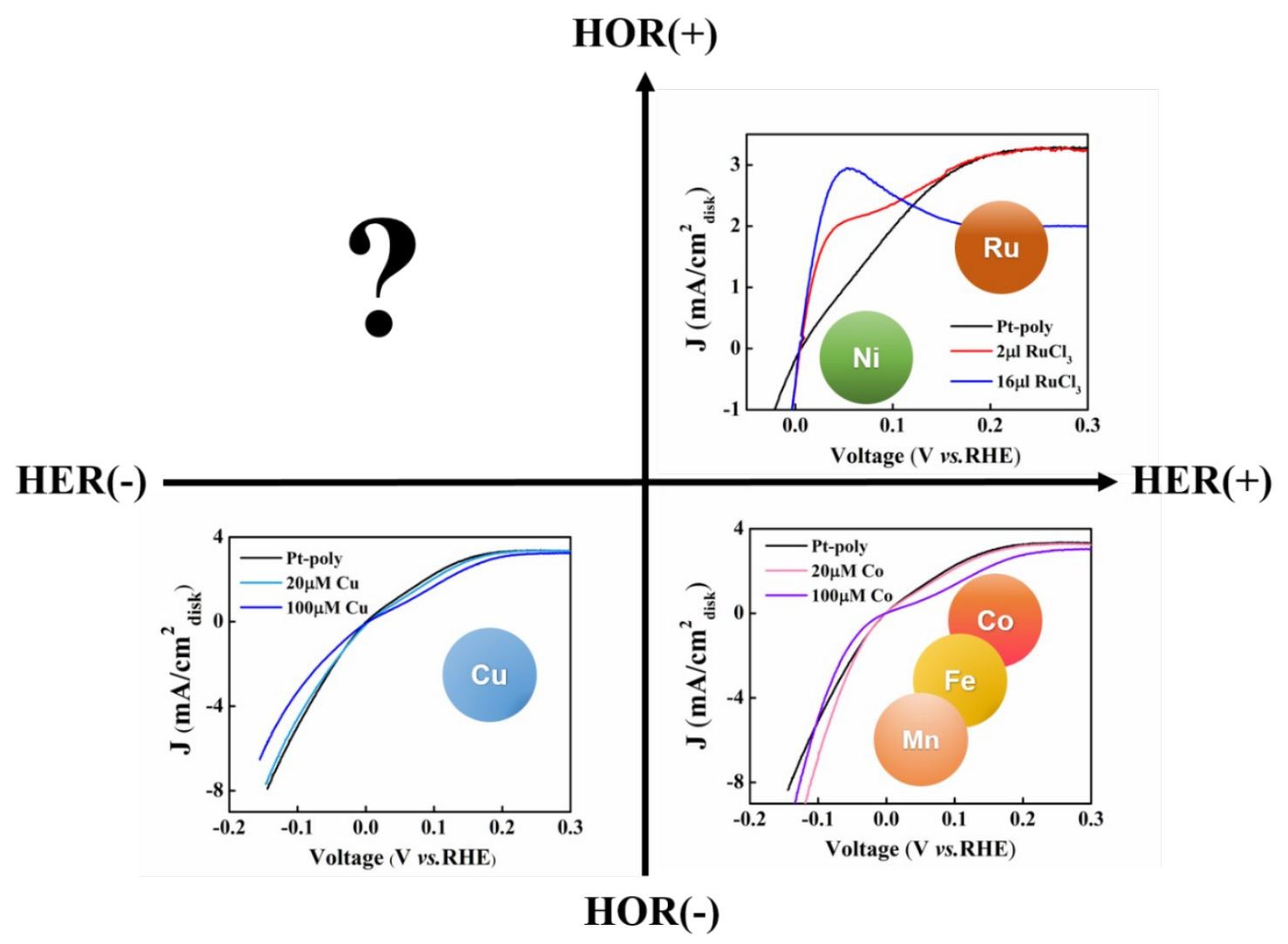

Figure 1. TM-induced changes of the HOR/HER rates of Pt. The HOR/HER polarization curves of the Pt polycrystalline electrode with/without surface deposition of Ru (quadrant I), $\mathrm{Cu}$ (quadrant III), and Co (quadrant IV) in an $\mathrm{H}_{2}$-saturated $0.1 \mathrm{M} \mathrm{KOH}$ electrolyte at room temperature. Scan rate: $10 \mathrm{mV} \cdot \mathrm{s}^{-1}$. Rotation rate: $2,500 \mathrm{rpm}$.

The highly diversified TM-induced modifications of the HOR/HER rates of Pt in alkaline solutions indicate the different roles played by different TMs with different oxophicility in 
affecting the HOR/HER kinetics of Pt. Accordingly, we conducted CO stripping experiments on the TM-deposited Pt electrode (except for Ru that is poisoned by $\mathrm{CO}^{23}$ ) since the TM oxophicility is known to play important roles in promoting the CO oxidation of Pt via the bifunctional mechanism. ${ }^{20,24}$ The TM-induced improvement of the CO oxidation of Pt decreases in the order of $\mathrm{Mn}>\mathrm{Fe} \sim \mathrm{Co}>\mathrm{Ni}>\mathrm{Cu}$ (Figure 2a), in agreement with the trend previously acquired by depositing $3 \mathrm{~d}$ metals onto $\operatorname{Pt}(111){ }^{20}{ }^{20}$ This trend consistently relates to the decreasing TMs' oxophicility in the same order, or equivalently the binding energy toward oxygen $\left(E_{M-0}\right){ }^{25}$ This trend is opposite to the HER trend of $\mathrm{Mn}<\mathrm{Fe} \sim \mathrm{Co}<\mathrm{Ni}$ reported here (Figure $2 \mathrm{~b}$ ) and elsewhere, ${ }^{7,20}$ except for $\mathrm{Cu}$ that has negligible effects on the HER kinetics of the Pt. These opposite trends can be rationalized by the reverse transport of hydroxyl throughout the IHP between the HER and CO oxidation (Figure 2). The HER involves releasing the TM-anchored $\mathrm{OH}_{\mathrm{ad}}$ into the electrolyte forming $\mathrm{OH}^{-}$as per the $\mathrm{HSAB}$ mechanism: $\mathrm{OH}_{\mathrm{ad}}-\left[\mathrm{AM}\left(\mathrm{H}_{2} \mathrm{O}\right)_{\mathrm{x}}\right]^{+}+\mathrm{e}^{-} \leftrightarrow$ $\mathrm{OH}^{-}\left[\mathrm{AM}\left(\mathrm{H}_{2} \mathrm{O}\right)_{\mathrm{x}}\right]^{+}, 6$ and is thus faster with weaker $\mathrm{E}_{\mathrm{M}-\mathrm{o}}$ until the $\mathrm{E}_{\mathrm{M}-\mathrm{o}}$ becomes too weak to effectively anchor $\mathrm{OH}_{\mathrm{ad}}$ (like $\mathrm{Cu}$ ) to trigger the $\mathrm{HSAB}$. Reversely, the $\mathrm{CO}$ oxidation involves bringing $\mathrm{OH}^{-}$from the electrolyte onto the surface $\mathrm{TM}$ forming $\mathrm{OH}_{\mathrm{ad}}$, and is faster with stronger $\mathrm{E}_{\mathrm{M}-\mathrm{O}}$. This reasoning is further supported by the opposite trends of the HER and CO oxidation with $\mathrm{AM}^{+}$concentration and $\mathrm{pH}$. We previously showed that the HER of Pt/C increases with increasing $\mathrm{AM}^{+}$concentration, ${ }^{6}$ since the $\left[\mathrm{AM}\left(\mathrm{H}_{2} \mathrm{O}\right)_{\mathrm{x}}\right]^{+}$facilitates the removal of $\mathrm{OH}_{\text {ad. }}$. This reasoning calls for the delay of the $\mathrm{CO}$ oxidation with increasing $\mathrm{AM}^{+}$concentration, which is indeed the case. ${ }^{6}$ Furthermore, the slower HER kinetics of Pt in alkaline than in acid can be ascribed to the need to transport hydroxyl, accordingly the superior CO oxidation kinetics in alkaline than in acid ${ }^{26}$ is attributable to the source of $\mathrm{OH}_{\text {ad }}$ directly from $\mathrm{OH}^{-}$rather than water dissociation. 


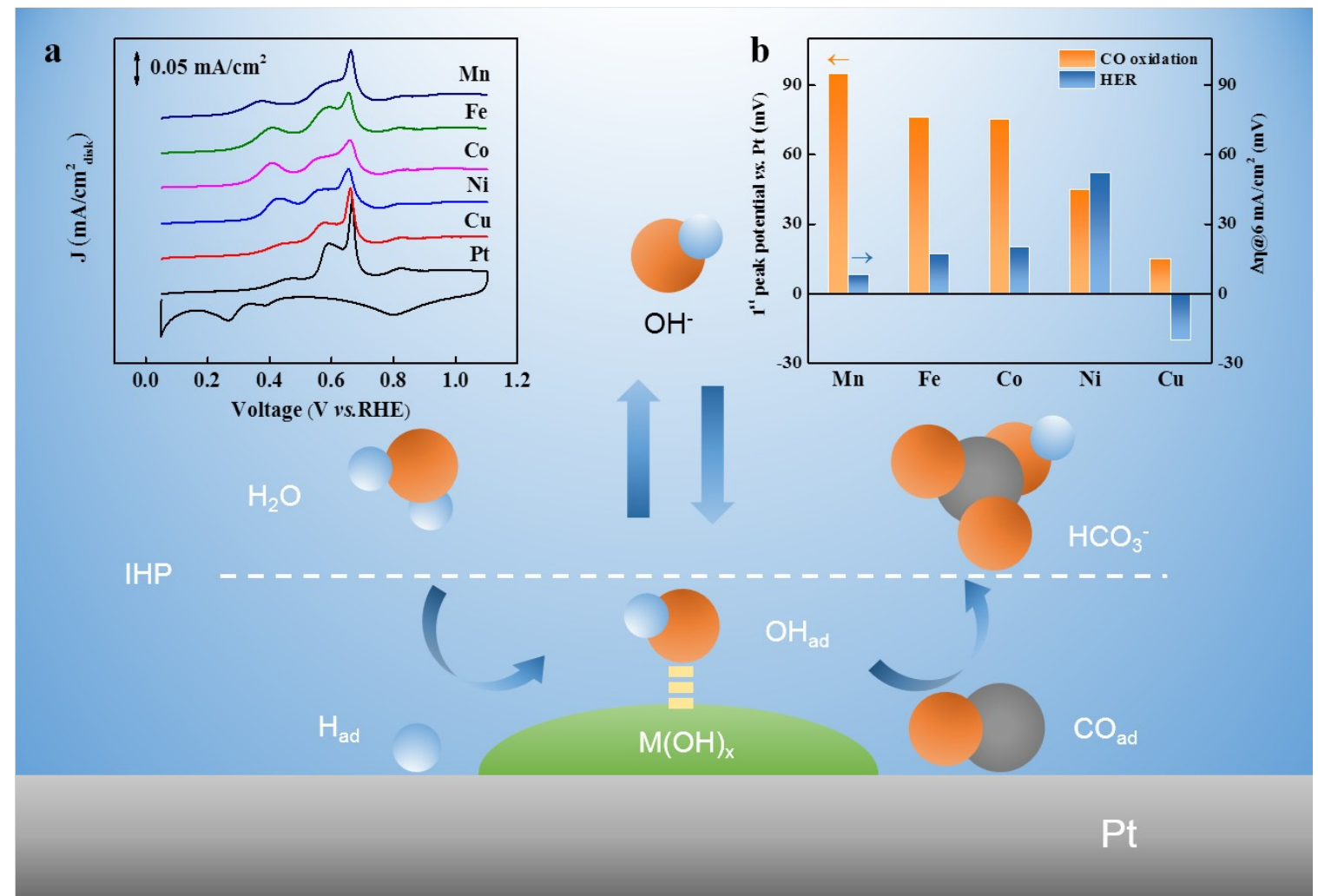

Figure 2. The opposite transport of hydroxyl throughout the IHP between the HER and CO oxidation in alkaline solutions. (a) Voltammetric profiles of CO stripping for Pt polycrystalline in an Ar-saturated 0.1 M KOH electrolyte with/without surface deposited TM (100 $\mu \mathrm{M})$. Scan rate: $20 \mathrm{mV} \cdot \mathrm{s}^{-1} \cdot E_{\mathrm{ads}}=0.05 \mathrm{~V}$ (all potentials here are versus the reversible hydrogen electrode). (b) The TM-induced HER and CO oxidation improvement of Pt polycrystalline in a $\mathrm{H}_{2}$ - and Arsaturated $0.1 \mathrm{M} \mathrm{KOH}$ electrolyte, respectively. $\Delta \eta$ represents the improvement of HER overpotential when current density reaches $6 \mathrm{~mA} / \mathrm{cm}^{2}$. Original HER polarization curves were given in Figure S2.

While the CO stripping experiments support the presence of $\mathrm{OH}_{\mathrm{ad}}$ on the surface TMs, they defy the bifunctional mechanism wherein the TM-anchored $\mathrm{OH}_{\mathrm{ad}}$ removes the $\mathrm{H}_{\mathrm{ad}}$ on the Pt neighbors, ${ }^{12,13}$ given that all the TMs improve the CO oxidation of Pt but only Ni improves the HOR. Even Ni facilitates both HOR and CO oxidation of Pt, the CO oxidation occurs above 0.3 V whereas the HOR improvement occurs below $0.1 \mathrm{~V}$ (Figure S3). ${ }^{6}$ If the $\mathrm{CO}_{\text {ad }}$ on Pt is removed by the $\mathrm{OH}_{\mathrm{ad}}$ on $\mathrm{Ni}$, the $\mathrm{H}_{\mathrm{ad}}$ on Pt must not be removed by the same $\mathrm{OH}_{\mathrm{ad}}$. The potential dependent HOR improvement induced by $\mathrm{Ni}$ is also observed on Ru that improves the HOR of Pt below $0.15 \mathrm{~V}$ (Figure 1, quadrant I), which was previous observed by us, ${ }^{12}$ and lately by Tang et al. ${ }^{11}$ As 
the Ru coverage increases, the HOR polarization curve reach the maximum around $0.05 \mathrm{~V}$, and drops drastically with increasing potential (Figure 1, quadrant I). This curve closely resembles the HOR curve of $\mathrm{Ru},{ }^{12,13}$ for which the drop is explained as the formation of hydr(oxy)oxides passivation layer. These results together suggest the $\mathrm{Ni}$ - or Ru-induced potential-dependent HOR improvement relates to its oxidation state that changes across the HOR/HER potential region. ${ }^{6,12}$

To monitor the dynamic oxidation states of the TMs deposited on Pt during the HOR/HER, in situ XAS was conducted at the K-edge of the TMs within the HOR/HER potential region in an $\mathrm{H}_{2}$-saturated $0.1 \mathrm{M} \mathrm{KOH}$ electrolyte. As the potential increases, the X-ray absorption near edge structure (XANES) spectra of all the TMs shift to higher energy towards those of the corresponding (hydr)oxide standards, indicating the oxidation of TMs. The changes of the oxidation state of various TMs with increasing potentials were quantitatively compared (Figure 3d). This is enabled by choosing the energy at which the XANES spectrum is at 0.3 ( $E_{\text {edge }}$ ) relative to those of the standards (STDs) to represent the oxidation state: $\left(n \times\left(\mathrm{E}_{\text {edge }}(T M)\right.\right.$ $\left.\mathrm{E}_{\text {edge }}\left(\mathrm{STD}^{0+}\right)\right) /\left(\left(\mathrm{E}_{\text {edge }}\left(\mathrm{STD}^{\mathrm{n}+}\right)-\mathrm{E}_{\text {edge }}\left(\mathrm{STD}^{0+}\right)\right)\right.$ wherein $\mathrm{n}+$ represents the valence of the $\mathrm{STD}(2+$ for $\mathrm{Ni}(\mathrm{OH})_{2}$ ), given that the oxidation state of TMs is nearly linearly related to the $\mathrm{E}_{\text {edge. }}{ }^{27} \mathrm{It}$ is clearly seen that $\mathrm{Co}$ is dominated by $\mathrm{Co}(\mathrm{OH})_{2}$ whereas $\mathrm{Cu}$ is dominated by metallic $\mathrm{Cu}^{0+}$ within the entire HER/HOR potential range. The increase of the oxidation state of Ni mainly occurs below $0 \mathrm{~V}$, and $\mathrm{Ni}(\mathrm{OH})_{2}$ dominates at positive potentials according to the XAS results we recently reported. ${ }^{6}$ This redox transition agrees with the $\mathrm{Ni} / \mathrm{Ni}(\mathrm{OH})_{2}$ redox potential of $0.05 \mathrm{~V}$ in $0.1 \mathrm{M}$ $\mathrm{KOH} .{ }^{28} \mathrm{Ru}$ is dominated by metallic $\mathrm{Ru}^{0}$ at negative potentials, and is progressively oxidized as the potential increases to $0.5 \mathrm{~V}$ (Figure 3c), which agrees well with the reversible $\mathrm{Ru} / \mathrm{Ru}(\mathrm{OH})_{3}$ transition between $0.2-0.8 \mathrm{~V}$ observed electrochemically. ${ }^{29-31}$ Theses results show that the 
phases and redox behaviors of these TMs are distinctly different within the HER/HOR potential range.
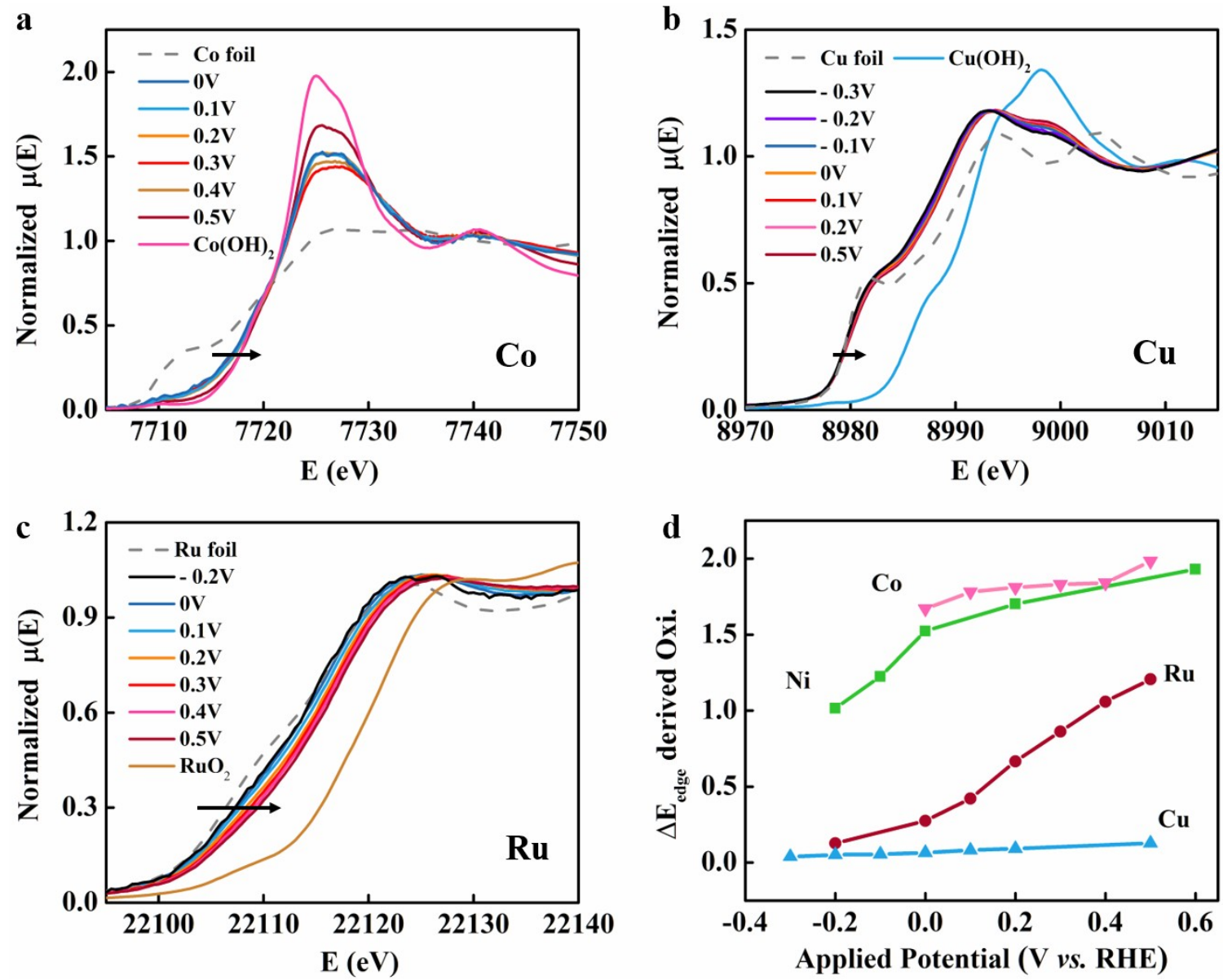

Figure 3. Redox transition of the TMs deposited on Pt/C reflected by XANES. K-edge XANES spectra of the (a) Co, (b) $\mathrm{Cu}$, and (c) Ru deposited onto Pt/C as a function of applied potentials collected in an $\mathrm{H}_{2}$-purged $0.1 \mathrm{M} \mathrm{KOH}$ electrolyte. (d) The oxidation states of TMs derived from the $E_{\text {edge }}$ acquired from (a-c), and of Ni from our previous work. ${ }^{6}$

The Fourier Transform of the extended X-ray absorption fine structure (FT-EXAFS) spectra of these TMs agree well with their corresponding XANES spectra. The deposited Co is dominated by the Co-O $(\sim 1.5 \AA)$ and Co-Co $(\sim 2.8 \AA)$ peaks overlapping those of the $\mathrm{Co}(\mathrm{OH})_{2}$ within the potential range of 0.1-0.5 V, and the Co-Co peak around $2.1 \AA$ seen in the Co foil is absent (Figure 4a). In contrast, a small Ni-Ni peak around $2.1 \AA$ overlapping that of Ni foil is clearly discernible at $0 \mathrm{~V}$, and vanishes at positive potentials. ${ }^{6}$ This reflects the presence of small 
amounts of metallic $\mathrm{Ni}^{0}$ phase at $0 \mathrm{~V}$ and its oxidation to $\mathrm{Ni}(\mathrm{OH})_{2}$ at higher potentials. The FTEXAFS spectra of $\mathrm{Cu}$ exhibit a prominent $\mathrm{Cu}-\mathrm{Cu}$ peak around $2.1 \AA$ overlapping that of the $\mathrm{Cu}$ foil (Figure $4 \mathrm{~b}$ ) between $-0.3-0.5 \mathrm{~V}$, which verifies the metallic $\mathrm{Cu}^{0}$ as the dominate phase. A small Cu-O peak around $1.5 \AA$ overlapping that of $\mathrm{Cu}(\mathrm{OH})_{2}$ are discernible at positive potentials, indicating the mild oxidation of $\mathrm{Cu}^{0}$ as also reflected by the minor XANES shift (Figure 3b).
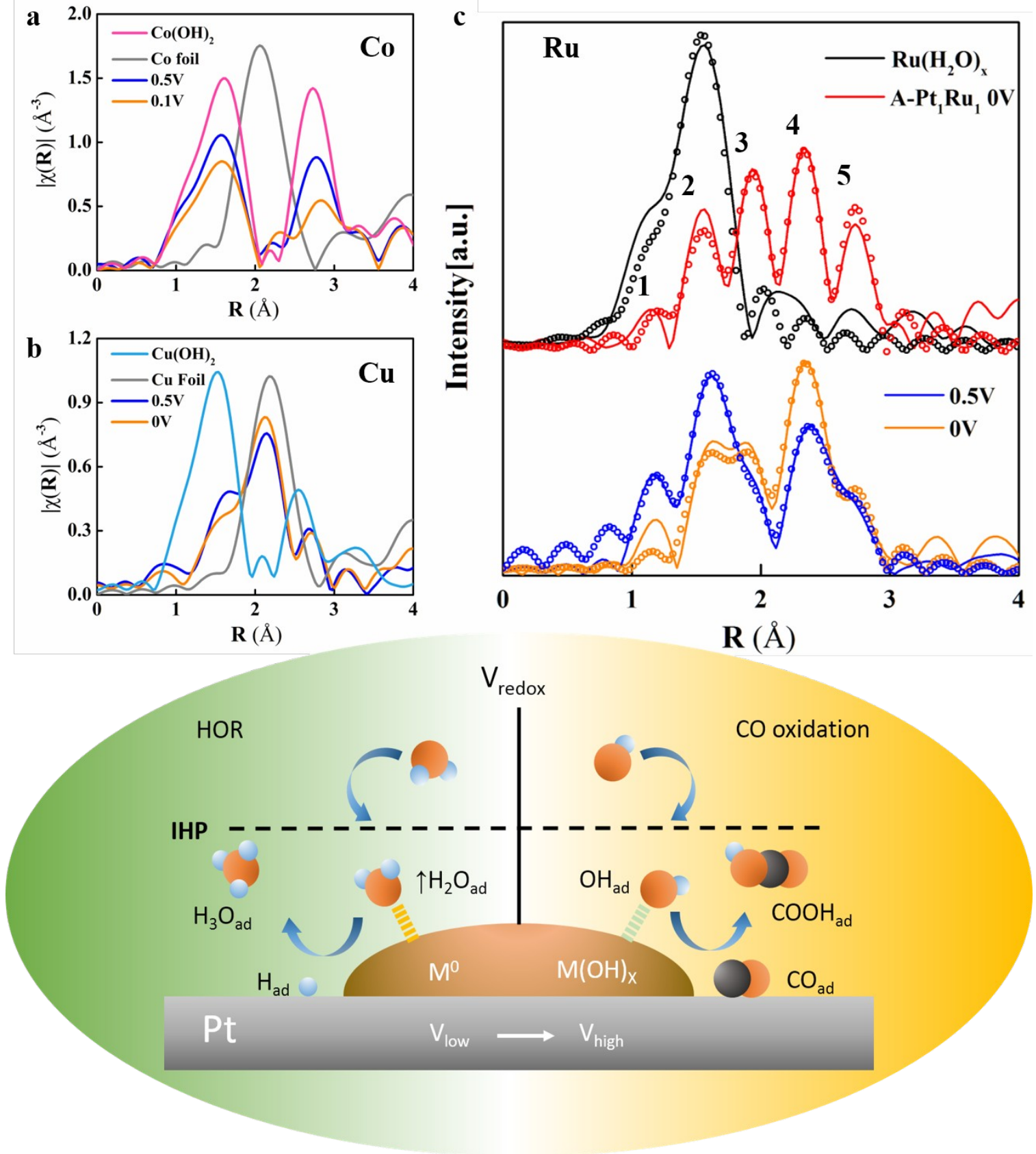
Figure 4. Redox transition of $\mathrm{TM}^{0} / \mathrm{TM}^{\mathrm{x}}$ during the HOR/HER. K-edge FT-EXAFS spectra of the (a) Co, (b) $\mathrm{Cu}$, and (c) Ru deposited onto $\mathrm{Pt} / \mathrm{C}$ as a function of applied potentials collected in an $\mathrm{H}_{2}$-purged $0.1 \mathrm{M} \mathrm{KOH}$ electrolyte. The scatter plots represent corresponding fittings of $\mathrm{Ru}$. The fitting results were given in Table S1 and S2. The bottom scheme illustrates the two different bifunctional mechanism for the HER enabled by $\uparrow \mathrm{H}_{2} \mathrm{O}_{\text {ad }}$ and for the CO oxidation enabled by $\mathrm{OH}_{\mathrm{ad}}$.

Unlike $\mathrm{Cu}$, the Ru FT-EXAFS spectrum at $0 \mathrm{~V}$ exhibits a prominent Ru-O peak around $1.5 \AA$, despite the predominate $\mathrm{Ru}^{0}$ phase indicated by XANES. The five peaks, which are also observed in the $\mathrm{Pt}_{1} \mathrm{Ru}_{1}$ alloy (ETEK, $29.1 \mathrm{wt} \%$ ) at $0 \mathrm{~V}$, can be fitted with a Pt-Ru alloying model combined with a Ru- $\mathrm{O}_{\mathrm{x}}$ model (Figure 4c). ${ }^{32}$ The fitting gives a coordination number of $3.1 \pm 0.8$ for the Ru-Pt bond, verifying the formation of the Pt-Ru alloying phase. A Ru-O bond with a coordination number of $0.9 \pm 0.3$ and bond length of $2.05 \pm 0.02 \AA$ is determined by fitting the scattering peak at $1.5 \AA$ (Table S1). The assignment of this peak exclusively to the Ru-O bond in $\mathrm{Ru}$ hydr(oxy)oxides however conflicts with the XAENS spectrum that indicates the $\mathrm{Ru}^{0}$ is the dominant phase. Furthermore, the Ru-O bond distance is longer than that of $\mathrm{RuO}_{2}(1.97 \pm 0.01$ $\AA$ ), but comparable to that of the $\mathrm{RuCl}_{3}$ solution (2.04 $\pm 0.01 \AA$ ) wherein the $\mathrm{Ru}$ is coordinated by $\mathrm{H}_{2} \mathrm{O}$ molecules (Table S3). We therefore assign this $\mathrm{Ru}-\mathrm{O}$ peak at $0 \mathrm{~V}$ to the bonding between the metallic $\mathrm{Ru}^{0}$ and the $\mathrm{O}$ from the specifically adsorbed $\uparrow \mathrm{H}_{2} \mathrm{O}$ molecules $\left(\uparrow \mathrm{H}_{2} \mathrm{O}_{\mathrm{ad}}-\mathrm{Ru}\right)$. As the potential increases to $0.5 \mathrm{~V}$, the intensities of the Ru-O peaks at $1.2 \AA$ and $1.5 \AA$ increase, whereas the intensities of the Ru-Ru/Pt peaks at $1.9 \AA$ and $2.4 \AA$ decrease. These results indicate the progressive adsorption of $\mathrm{H}_{2} \mathrm{O}$ onto the surface $\mathrm{Ru}$, followed by $\uparrow \mathrm{H}_{2} \mathrm{O}_{\text {ad }}$ dissociation leading to the formation of $\mathrm{Ru}(\mathrm{OH})_{3}$ as the potential increases to $0.5 \mathrm{~V}$.

The redox transition of Ru correlates well to the potential dependent Ru-induced improvement of the HOR of Pt (Figure 1). The HOR improvement is substantial at $0 \mathrm{~V}$ when the surface $\mathrm{Ru}$ is dominated by metallic $\mathrm{Ru}^{0}$ that can anchor $\uparrow \mathrm{H}_{2} \mathrm{O}_{\text {add }}$. The improvement gradually vanishes with the formation of $\mathrm{Ru}(\mathrm{OH})_{3}$ as the potential increases. This correlation implicates 
that it is the metallic $\mathrm{Ru}^{0}$ rather than $\mathrm{Ru}(\mathrm{OH})_{3}$ that improves the HOR of Pt. This implication is applicable to other TMs. The marginal HOR improvement induced by the surface Ni below $0.1 \mathrm{~V}$ is accompanied with the weak but discernible FT-EXAFS signals of $\mathrm{Ni}^{0}$, and the $\mathrm{Ni} / \mathrm{Ni}(\mathrm{OH})_{2}$ redox potential of $0.05 \mathrm{~V}^{28}$ This redox-active behavior of $\mathrm{Ni}$ and $\mathrm{Ru}$ within the HOR kinetic potential region of Pt clearly signifies their ability to attract the $\mathrm{H}_{2} \mathrm{O}$ into the IHP forming $\uparrow \mathrm{H}_{2} \mathrm{O}_{\text {ad: }}: \mathrm{TM}^{0}+\mathrm{H}_{2} \mathrm{O} \leftrightarrow \uparrow \mathrm{H}_{2} \mathrm{O}_{\text {ad }}-\mathrm{TM}^{0} \leftrightarrow \mathrm{TM}(\mathrm{OH})_{\mathrm{x}}$. No HOR improvement was observed on Co that is dominated by $\mathrm{Co}(\mathrm{OH})_{2}$ with indiscernible $\mathrm{Co}^{0} \mathrm{FT}$-EXAFS signals within the HOR potential region, and Fe and $\mathrm{Mn}$ with even higher oxophicility. The $\mathrm{Cu}$ is dominated by $\mathrm{Cu}^{0}$ that is however incapable of anchor $\uparrow \mathrm{H}_{2} \mathrm{O}_{\text {ad }}$ before Pt reaches the HOR mass transport limit by 0.25 $\mathrm{V}^{33}$ as reflected by the indiscernible XAS signals of $\uparrow \mathrm{H}_{2} \mathrm{O}_{\mathrm{ad}}-\mathrm{Cu}$. Based on the foregoing electrochemical and XAS results, we propose that it is the $\uparrow \mathrm{H}_{2} \mathrm{O}_{\text {ad }}$ anchored on metallic $\mathrm{TM}^{0}$ that removes the $\mathrm{H}_{\mathrm{ad}}$ from the Pt for the $\mathrm{HOR}$, whereas the $\mathrm{OH}_{\mathrm{ad}}$ hosted on $\mathrm{TM}$ hydr(oxy)oxides removes the $\mathrm{CO}_{a d}$ from the $\mathrm{Pt}$ for $\mathrm{CO}$ oxidation (Figure 4). As for the TM with a too low redox potential of $\mathrm{TM}^{0} / \mathrm{TM}^{\mathrm{x}}$ (denoted as $\mathrm{V}_{\text {redox }}$ ) such as $\mathrm{Mn}, \mathrm{Fe}$, and Co, the metallic $\mathrm{TM}^{0}$ phase is absent at the HOR region and therefore it can't improve the HOR of Pt but improve the CO oxidation. On the other hand, the TM with a too high $\mathrm{V}_{\text {redox }}$ such as Cu can't effectively anchor $\uparrow \mathrm{H}_{2} \mathrm{O}_{\text {ad }}$ below $0.25 \mathrm{~V}$ and thus can’t improve the HOR kinetics of Pt neither, but may improve the CO oxidation at more positive potentials. Finally, the TM with a moderate $\mathrm{V}_{\text {redox }}$ such as $\mathrm{Ni}$ and $\mathrm{Ru}$ improves the HOR kinetics of Pt within the potential region wherein it can anchor $\uparrow \mathrm{H}_{2} \mathrm{O}_{\text {ad }}$ but without breaking it. The improvement vanishes with the dissociation of $\uparrow \mathrm{H}_{2} \mathrm{O}_{\text {ad }}$ leading to the formation of hydr(oxy)oxides at more positive potentials.

The revised bifunction mechanism describes that the surface TM facilitates the HOR of Pt in alkaline solutions by anchoring $\uparrow \mathrm{H}_{2} \mathrm{O}_{\text {ad }}$ that releases the intermediate $\mathrm{H}_{\text {ad }}$. Meanwhile, the 
HSAB mechanism we proposed previously ${ }^{6}$ describes that the surface TM improves the HER of Pt by anchoring the intermediate $\mathrm{OH}_{\text {ad }}$ that is later released by $\left[\mathrm{AM}\left(\mathrm{H}_{2} \mathrm{O}\right)_{\mathrm{x}}\right]^{+}$. The combined 2B theory implicates that the sluggish HOR/HER kinetics of Pt in alkaline solutions is limited by the transport of reaction intermediates, in line with the pzfc theory. ${ }^{14}$ The pzfc theory fully accounts for the $\mathrm{pH}$-dependence of the HOR/HER kinetics of Pt(111) ${ }^{14}$ that cannot host $\uparrow \mathrm{H}_{2} \mathrm{O}_{\text {ad }}$ or $\mathrm{OH}_{\mathrm{ad}}$ within the HOR/HER potential region ${ }^{34}$ so the 2B theory is inapplicable, and the $\mathrm{H}_{\mathrm{ad}}$ or $^{\mathrm{O}} \mathrm{H}^{-}$is transported by $\uparrow \mathrm{H}_{2} \mathrm{O}$ with the orientation dictated solely by the pzfc. Resultantly, the HER/HOR kinetics of $\mathrm{Pt}(111)$ is unaffected by $\mathrm{AM}^{+}$identity and concentration. ${ }^{10}$ The pzfc also accounts for the $\mathrm{pH}$-dependent HOR/HER rates of non- $\mathrm{Pt}(111)$ surfaces such as $\mathrm{Pt}(110)$, but the 2B theory also applies since the $\mathrm{Pt}(110)$ can anchor $\uparrow \mathrm{H}_{2} \mathrm{O}_{\mathrm{ad}}$ or $\mathrm{OH}_{\mathrm{ad}}$ within the HOR/HER potential region, ${ }^{34}$ due probably to the higher surface charge ${ }^{35}$ and/or stronger $\mathrm{E}_{\mathrm{M}-\mathrm{O}}{ }^{36}$ with lower coordination numbers. This explains why the HOR/HER kinetics of $\operatorname{Pt}(110)$ is superior to that of $\operatorname{Pt}(111){ }^{.}{ }^{5}$ The sensitivity of the HER of non-Pt(111) to $\mathrm{AM}^{+}$identity and concentration in alkaline solutions is manifested by the HSAB mechanism. ${ }^{6}$ The HOR is insensitive to $\mathrm{AM}^{+}$concentration since the HSAB mechanism is irrelevant. It is sensitive to $\mathrm{AM}^{+}$identity because the $\uparrow \mathrm{H}_{2} \mathrm{O}_{\text {ad }}$ competes with $\mathrm{H}_{\text {ad }}$ for Pt sites. As the $\uparrow \mathrm{H}_{2} \mathrm{O}_{\text {ad }}$-Pt binding energy in alkaline solutions decreases in the order of $\mathrm{Li}^{+}>\mathrm{Na}^{+}>\mathrm{K}^{+}, 34$ the $\uparrow \mathrm{H}_{2} \mathrm{O}_{\mathrm{ad}}$ replaces $\mathrm{H}_{\mathrm{ad}}$ at more positive potentials, delaying the bifunctional HOR. In this regard, the 2B theory agrees with the refined HBE theory wherein the comparative binding energy between the Pt- $\mathrm{H}_{\mathrm{ad}}$ and $\uparrow \mathrm{H}_{2} \mathrm{O}_{\mathrm{ad}}$-Pt dictates the HOR activity of Pt. ${ }^{19}$ An important implication derived from this argument is that the sharp underpotential-deposited hydrogen ( $\mathrm{H}_{\mathrm{UPD}}$ ) desorption peak of stepped Pt surfaces or Ru is caused by the replacement of $\mathrm{H}_{\mathrm{ad}}$ by $\uparrow \mathrm{H}_{2} \mathrm{O}_{\mathrm{ad}}$, but rather than $\mathrm{OH}_{\mathrm{ad}} .{ }^{34}$ Accordingly, the $\mathrm{H}_{\text {UpD }}$ peak of stepped Pt surfaces at lower potential in $\mathrm{LiOH}$ than in $\mathrm{KOH}$ signifies the early replacement of $\mathrm{H}_{\mathrm{ad}}$ by $\uparrow \mathrm{H}_{2} \mathrm{O}_{\text {ad }}$ and thus better 
HOR kinetics, whereas the absence of the $\mathrm{H}_{\text {UPD }}$ peak for $\mathrm{Pt}(111)$ signifies the absence of $\uparrow \mathrm{H}_{2} \mathrm{O}_{\mathrm{ad}}$ within the $\mathrm{H}_{\mathrm{UPD}}$ region.

The coherent picture of the HOR/HER kinetics of Pt in aqueous solutions depicted by the combined 2B theory and pzfc theory underlines the importance of $\mathrm{H}_{2} \mathrm{O}$ in transporting reaction intermediates. In principle, this study shows that the interface matters.

\section{Methods}

Chemicals. Carbon supported platinum nanoparticles (Pt/C, 47.2 wt.\%) were purchased from Tanaka Kikinzoku Kogyo. Copper(II) perchlorate hexahydrate $\left(\mathrm{Cu}\left(\mathrm{ClO}_{4}\right)_{2} \cdot 6 \mathrm{H}_{2} \mathrm{O}, 98 \%\right)$, nickel(II) perchlorate hexahydrate $\left(\mathrm{Ni}\left(\mathrm{ClO}_{4}\right)_{2} \cdot 6 \mathrm{H}_{2} \mathrm{O}, 99.99 \%\right)$, cobalt(II) perchlorate hexahydrate $\left(\mathrm{Co}\left(\mathrm{ClO}_{4}\right)_{2} \cdot 6 \mathrm{H}_{2} \mathrm{O}, 99 \%\right)$, iron(III) perchlorate hydrate $\left(\mathrm{Fe}\left(\mathrm{ClO}_{4}\right)_{3} \cdot \mathrm{H}_{2} \mathrm{O}\right.$, crystalline, low chloride), manganese(II) perchlorate hydrate $\left(\mathrm{Mn}\left(\mathrm{ClO}_{4}\right)_{2} \cdot \mathrm{xH}_{2} \mathrm{O}, 99 \%\right)$, potassium hydroxide $(\mathrm{KOH}$, 99.99\%), perchloric acid ( $\mathrm{HClO}_{4}, 70 \%$, PPT Grade) were all purchased from Sigma-Aldrich. All aqueous solutions were prepared using deionized (DI) water $(18.2 \mathrm{M} \Omega \cdot \mathrm{cm})$ obtained from an ultra-pure purification system (Aqua Solutions).

Electrode preparation. Prior to the electrodeposition, the glass carbon electrode embedded in PTFE or the Pt polycrystalline electrode was polished mechanically by $0.5 \mu \mathrm{m}, 0.3 \mu \mathrm{m}, 0.05 \mu \mathrm{m}$ alumina powder and then sonicated in sequence for 5 minutes in DI water and ethanol.

Electrochemical measurements. All the electrochemical experiments were conducted using a three-electrode cell system. Pt wire and $\mathrm{Ag} / \mathrm{AgCl}\left(1 \mathrm{M} \mathrm{Cl}^{-}\right)$reference electrode were used as the counter and reference electrodes respectively. All potentials reported in this paper are referenced to the reversible hydrogen electrode (RHE), calibrated in the same electrolyte by measuring the potential of the HOR/HER currents at zero corresponding to $0 \mathrm{~V}$ versus RHE ( $\mathrm{V}_{\mathrm{RHE}}$ ). 
Prior to the RDE testing in alkaline, Pt polycrystalline electrode were cycled with a rotation rate of 1,600 rpm in an Ar-saturated $0.1 \mathrm{M} \mathrm{HClO}_{4}$ electrolyte with a scan rate of $500 \mathrm{mVs}^{-1}$ between the potential range of $0.05-1.2 \mathrm{~V}_{\mathrm{RHE}}$ for 100 cycles following the Department of Energy (DOE) recommended protocol. ${ }^{37}$ Typical experimental procedures for HER/HOR experiments can be referred to our previous work. ${ }^{6}$

Impedance measurements: the impedance spectra were measured with frequencies from $10^{5}$ to $0.1 \mathrm{~Hz}$ with amplitude of $10 \mathrm{mV}$ by Autolab. Equivalent circuits were fitted to the data with Zview software.

Electrochemical deposition of $\left.\mathrm{M}\left(\mathrm{ClO}_{4}\right)_{2} \quad \mathrm{M}=\mathrm{Mn}, \mathrm{Co}, \mathrm{Ni}, \mathrm{Cu}\right), \mathrm{Fe}\left(\mathrm{ClO}_{4}\right)_{3}$ and $\mathrm{RuCl} \mathrm{Cl}_{3}$ : after the CV and HER/HOR measurements of the Pt polycrystalline, the electrode was unmounted from the RDE and immersed in $20 \mu \mathrm{M} \mathrm{M}\left(\mathrm{ClO}_{4}\right)_{2}$ for 1 minute. Then the HER/HOR polarization curves and the $\mathrm{CV}$ were recorded in a $\mathrm{H}_{2} / \mathrm{Ar}$-saturated $0.1 \mathrm{M} \mathrm{KOH}$ electrolyte under identical conditions as those of Pt polycrystalline. This process was repeated with increasing concentration of $\mathrm{M}\left(\mathrm{ClO}_{4}\right)_{2}$ until $100 \mu \mathrm{M}$. Electrochemical deposition for $\mathrm{RuCl}_{3}$ deposition followed our previous study. ${ }^{12}$

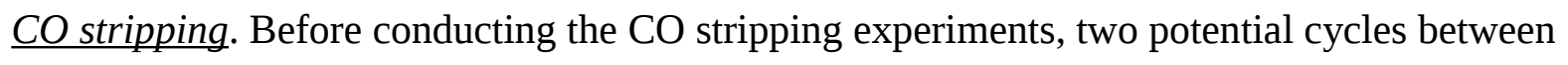
0.05 and $1.1 \mathrm{~V}_{\mathrm{RHE}}$ in $0.1 \mathrm{M} \mathrm{KOH}$ with scan rate of $20 \mathrm{mV} \cdot \mathrm{s}^{-1}$ were applied to the electrode before the adsorption of carbon monoxide by dosing the gas at a constant potential of $0.05 \mathrm{~V}_{\mathrm{RHE}}$ for 5 minutes into the solution, and then Ar was purged into the same electrolyte for 25 minutes at the same potential to remove the CO from the electrolyte.

In situ XAS data collection and analysis. The preparation method of the XAS electrodes can be referred to our previous work..$^{38,39}$ The final Pt geometric loadings were chosen to give 0.5 transmission spectra edge heights at the $\mathrm{Pt}_{3}$ edge. The XAS experiments were conducted at 
room temperature in a previously described flow half-cell in which continuously $\mathrm{H}_{2}$-purged 0.1 $\mathrm{M} \mathrm{KOH}$ was circulated. The voltage cycling limits were -0.3 to $0.6 \mathrm{~V}_{\mathrm{RHE}}$. The data at the $\mathrm{Cu}$ and Co edges of the Pt/C immersed in $\mathrm{Cu}\left(\mathrm{ClO}_{4}\right)_{2}, \mathrm{Co}\left(\mathrm{ClO}_{4}\right)_{2}$ solutions were collected in the fluorescence mode at the beamline ISS 8-ID, the data at the Ru edge of Pt/C immersed in $\mathrm{RuCl}_{3}$ were collected in 7-BM and the data of $\mathrm{RuO}_{2}$ standard were collected in 6-BM of the National Synchrotron Light Source (NSLS) II, Brookhaven National Laboratory (BNL). Typical experimental procedures were utilized with details provided in our previous work. ${ }^{38,39}$

\section{References}

1. Erdey-Gruz, T. \& Volmer, M. The theory of hydrogen overvoltage. Z. Phys. Chem 150, 203 (1930).

2. Trasatti, S. Work function, electronegativity, and electrochemical behaviour of metals: III. Electrolytic hydrogen evolution in acid solutions. J. electroanal. chem. interfacial electrochem. 39, 163-184 (1972).

3. Skúlason, E. et al. Modeling the electrochemical hydrogen oxidation and evolution reactions on the basis of density functional theory calculations. J. Phys. Chem. C 114, 18182-18197 (2010).

4. Herranz, J. et al. Interfacial effects on the catalysis of the hydrogen evolution, oxygen evolution and $\mathrm{CO}_{2}$-reduction reactions for (co-)electrolyzer development. Nano Energy 29, 428 (2016).

5. Schmidt, T. J., Ross, P. N. \& Markovic, N. M. Temperature dependent surface electrochemistry on Pt single crystals in alkaline electrolytes: Part 2. The hydrogen evolution/oxidation reaction. J. Electroanal. Chem. 524-525, 252-260 (2002). 
6. Liu, E. et al. Unifying the hydrogen evolution and oxidation reactions kinetics in base by identifying the catalytic roles of hydroxyl-water-cation adducts. J. Am. Chem. Soc. 141, 32323239 (2019).

7. Rebollar, L., Intikhab, S., Snyder, J. D. \& Tang, M. H. Determining the viability of hydroxidemediated bifunctional HER/HOR mechanisms through single-crystal voltammetry and microkinetic modeling. J. Electrochem. Soc. 165, J3209-J3221 (2018).

8. Danilovic, N. et al. The Effect of noncovalent interactions on the HOR, ORR, and HER on $\mathrm{Ru}$, Ir, and $\mathrm{Ru}_{0.50} \mathrm{I}_{0.50}$ metal surfaces in alkaline environments. Electrocatalysis 3, 221-229 (2012).

9. Subbaraman, R. et al. Enhancing hydrogen evolution activity in water splitting by tailoring Li+-Ni (OH) 2-Pt interfaces. Science 334, 1256-1260 (2011).

10. Strmcnik, D. et al. The role of non-covalent interactions in electrocatalytic fuel-cell reactions on platinum. Nat. Chem. 1, 466 (2009).

11. Intikhab, S. et al. Exploiting dynamic water structure and structural sensitivity for nanoscale electrocatalyst design. Nano Energy 64, 103963 (2019).

12. Li, J. et al. Experimental proof of the bifunctional mechanism for the hydrogen oxidation in alkaline media. Angew. Chem. Int. Ed. 56, 15594-15598 (2017).

13. Strmcnik, D. et al. Improving the hydrogen oxidation reaction rate by promotion of hydroxyl adsorption. Nat. Chem. 5, 300-306 (2013).

14. Ledezma-Yanez, I. et al. Interfacial water reorganization as a pH-dependent descriptor of the hydrogen evolution rate on platinum electrodes. Nat. Energy 2, 17031 (2017).

15. Sheng, W. et al. Correlating hydrogen oxidation and evolution activity on platinum at different pH with measured hydrogen binding energy. Nat. Commun. 6 (2015). 
16. Lu, S. \& Zhuang, Z. Investigating the influences of the adsorbed species on catalytic activity for hydrogen oxidation reaction in alkaline electrolyte. J. Am. Chem. Soc. 139, 5156-5163 (2017).

17. Van der Niet, M. J., Garcia-Araez, N., Hernández, J., Feliu, J. M. \& Koper, M. T. Water dissociation on well-defined platinum surfaces: The electrochemical perspective. Catal. Today 202, 105-113 (2013).

18. Zheng, J., Sheng, W., Zhuang, Z., Xu, B. \& Yan, Y. Universal dependence of hydrogen oxidation and evolution reaction activity of platinum-group metals on $\mathrm{pH}$ and hydrogen binding energy. Sci. Adv. 2 (2016).

19. Zheng, J., Nash, J., Xu, B. \& Yan, Y. Perspective—towards establishing apparent hydrogen binding energy as the descriptor for hydrogen oxidation/evolution reactions. J. Electrochem. Soc. 165, H27-H29 (2018).

20. Subbaraman, R. et al. Trends in activity for the water electrolyser reactions on $3 \mathrm{~d} \mathrm{M}(\mathrm{Ni}$, Co, Fe, Mn) hydr(oxy)oxide catalysts. Nat. Mater. 11, 550-557 (2012).

21. Danilovic, N. et al. Enhancing the alkaline hydrogen evolution reaction activity through the bifunctionality of $\mathrm{Ni}(\mathrm{OH})_{2} /$ metal catalysts. Angew. Chem. Int. Ed. 51, 12495-12498 (2012).

22. Intikhab, S., Snyder, J. D. \& Tang, M. H. Adsorbed hydroxide does not participate in the volmer step of alkaline hydrogen electrocatalysis. ACS Catal. 7, 8314-8319 (2017).

23. Marković, N. M. \& Ross, P. N. Surface science studies of model fuel cell electrocatalysts. Surf. Sci. Rep. 45, 117-229 (2002).

24. Watanabe, M. \& Motoo, S. Electrocatalysis by ad-atoms: Part II. Enhancement of the oxidation of methanol on platinum by ruthenium ad-atoms. J. electroanal. chem. interfacial electrochem. 60, 267-273 (1975). 
25. Rankin, R. B. \& Greeley, J. Trends in selective hydrogen peroxide production on transition metal surfaces from first principles. ACS Catal. 2, 2664-2672 (2012).

26. García, G. Correlation between CO oxidation and H adsorption/desorption on Pt surfaces in a wide ph range: the role of alkali cations. ChemElectroChem 4, 459-462 (2017).

27. Jia, Q. et al. Metal and metal oxide interactions and their catalytic consequences for oxygen reduction reaction. J. Am. Chem. Soc. 139, 7893-7903 (2017).

28. Sheng, W., Myint, M., Chen, J. G. \& Yan, Y. Correlating the hydrogen evolution reaction activity in alkaline electrolytes with the hydrogen binding energy on monometallic surfaces. Energy Environ. Sci. 6, 1509-1512 (2013).

29. Juodkazytė, J., Vilkauskaitė, R., Stalnionis, G., Šebeka, B. \& Juodkazis, K. EQCM study of $\mathrm{Ru}$ and $\mathrm{RuO}_{2}$ surface electrochemistry. Electroanalysis 19, 1093-1099 (2007).

30. Sugawara, Y., Yadav, A., Nishikata, A. \& Tsuru, T. EQCM study on dissolution of ruthenium in sulfuric acid. J. Electrochem. Soc. 155, B897-B902 (2008).

31. Povar, I. \& Spinu, O. Ruthenium redox equilibria 3. Pourbaix diagrams for the systems Ru$\mathrm{H}_{2} \mathrm{O}$ and Ru-Cl- $\mathrm{H}_{2} \mathrm{O}$. Journal of Electrochemical Science and Engineering 6, 145-153 (2016).

32. Alayoglu, S. et al. Structural and architectural evaluation of bimetallic nanoparticles: a case study of Pt-Ru core-shell and alloy nanoparticles. ACS Nano 3, 3127-3137 (2009).

33. Sheng, W., Gasteiger, H. A. \& Shao-Horn, Y. Hydrogen oxidation and evolution reaction kinetics on platinum: acid vs alkaline electrolytes. J. Electrochem. Soc. 157, B1529-B1536 (2010).

34. McCrum, I. T. \& Janik, M. J. pH and alkali cation effects on the pt cyclic voltammogram explained using density functional theory. J. Phys. Chem. C 120, 457-471 (2016). 
35. Abbas, Z., Labbez, C., Nordholm, S. \& Ahlberg, E. Size-dependent surface charging of nanoparticles. J. Phys. Chem. C 112, 5715-5723 (2008).

36. Calle-Vallejo, F. et al. Finding optimal surface sites on heterogeneous catalysts by counting nearest neighbors. Science 350, 185-189 (2015).

37. Kocha, S. S. et al. Best practices and testing protocols for benchmarking orr activities of fuel cell electrocatalysts using rotating disk electrode. Electrocatalysis 8, 366-374 (2017).

38. Jia, Q. et al. Activity descriptor identification for oxygen reduction on platinum-based bimetallic nanoparticles: in situ observation of the linear composition-strain-activity relationship. Acs Nano 9, 387-400 (2015).

39. Jia, Q. et al. Circumventing metal dissolution induced degradation of Pt-alloy catalysts in proton exchange membrane fuel cells: revealing the asymmetric volcano nature of redox catalysis. ACS Catal. 6, 928-938 (2016).

\section{Acknowledgements}

This work was supported by the Office of Naval Research (ONR) under award number N000141712608 and the Graduate Thesis/Dissertation Grant of Northeastern University. The authors declare no competing financial interests. This research used beamline 6-BM, 7-BM and 8-ID (ISS) of the National Synchrotron Light Source II, a U.S. Department of Energy (DOE) Office of Science User Facility operated for the DOE Office of Science by Brookhaven National Laboratory under Contract No. DE-SC0012704. 